\title{
NEUROLINGUÍSTICA DISCURSIVA E TRANSMISSÃO - A QUESTÃO DA AUTORIA
}

\author{
SILVANA PEROTTINO ${ }^{1}$
}

(GPAL)

\begin{abstract}
RESUMO: O objetivo deste artigo é desenvolver a ideia de que a noção de autoria deva ser discutida na/para a Neurolinguística Discursiva, área fundada por Coudry na década de 80. Com essa finalidade, recorremos às ideias de Foucault $(2009,2011)$ sobre autoria. Pretendemos vincular essa noção diretamente a uma concepção de sujeito formulada pela $\mathrm{ND}$, bem como ao tipo de acompanhamento realizado nos grupos de convivência e/ou nos atendimentos longitudinais individuais. Há uma marca, compreendida como o modo de se dirigir e se referir aos sujeitos, instauradora de uma diferença fundamental nos estudos da linguagem no contexto patológico. A verificação dessa hipótese se faz por meio de um levantamento preliminar da escrita de casos - afasias, autismos - na Neurolinguística Discursiva.
\end{abstract}

Palavras-chave: Neurolinguística Discursiva; afasia; autismo.

ABSTRACT: The aim of this article is to exploit the idea that the notion of authorship has to be discussed within/for the field of Discursive Neurolinguistics, area founded by Coudry in the 80s. Bearing this in mind, we resorted to Foucault's ideas $(2009,2011)$ about authorship. Our intention is to link this notion directly to the concept of subject devised by Discursive Neurolinguistics, as well as to the kind of follow up support provided for the social groups and/or in longitudinal individual care. There is a mark, known as the way of addressing and referring to the subjects, which sets up a fundamental distinction into the studies of language within the pathological context. This hypothesis verification is carried out through a preliminary survey into the writing of clinical cases - aphasia, autism - within the field of Discursive Neurolinguistics.

Keywords: Discursive Neurolinguistics; aphasia; autism.

\section{INTRODUÇÃO}

A tese de Maria Irma Hadler Coudry, Diário de Narciso: discurso e afasia, defendida em 1986, e publicada posteriormente como livro, em 1988, com título homônimo, inaugurou uma teorização inédita a respeito da relação cérebro-mente-linguagem. A sua (re)formulação, desde então, pôde ser realizada por meio de projetos coordenados pela própria pesquisadora no Departamento de Linguística do Instituto de Estudos da Linguagem da Unicamp: o Projeto Integrado em Neurolinguística: práticas com a linguagem e a documentação de dados, de 1992-2013 e o Projeto Neurolinguística Discursiva: práticas com a linguagem e banco de dados, em andamento desde 2008. A importância dessa

\footnotetext{
${ }^{1}$ silvana-perotino@uol.com.br
} 
proposta - uma Neurolinguística de orientação enunciativo-discursiva - no meio acadêmico é corroborada por meio do grande número de orientações realizadas por Coudry, de artigos e de livros publicados, bem como de palestras em eventos científicos ou de divulgação para profissionais de diversas áreas (linguistas, educadores, fonoaudiólogos, médicos, psicopedagogos etc). Além disso, o alcance dessa proposta vem se dando em termos de mudanças na avaliação e no acompanhamento - seja no âmbito clínico ou não - de sujeitos considerados como "portadores" de déficits de/na linguagem.

É fundamental destacar o alcance da reflexão inicial de Coudry a respeito do sujeito afásico e do discurso, em que a afasia passa a ser compreendida como "alterações em processos de significação relacionados aos níveis linguísticos e às suas relações e interfaces" (Coudry, 2002, p. 111). Ao considerar a necessidade de avaliar e realizar o acompanhamento longitudinal dos sujeitos afásicos em situações concretas de interlocução - fundamentadas em teorias de linguagem, de língua e de sujeito oriundas da Linguística -, diversos pesquisadores e clínicos, instigados e críticos de teorias e de práticas nas quais era patente a sobreposição da patologia no lugar do sujeito afetado por ela, uniram-se ao redor dessa proposta. Esse esforço de teorização foi se estendendo para outros campos, como no caso da educação, tendo como foco a questão do processo de subjetivação da criança na escrita (mesmo a relação sujeito-linguagem não sendo cogitada pelas instituições educacionais), a partir do momento em que se constatou as tentativas generalizadas - da escola e de especialistas - de patologizar o aprendiz da escrita, atribuindo a ele rótulos como dislexia, transtornos do déficit de atenção e/ou hiperatividade, problemas no processamento auditivo e/ou dificuldade de aprendizagem.

O objetivo deste artigo é desenvolver a ideia de que deva ser reconhecida a noção de autoria para a Neurolinguística Discursiva (doravante ND), já que o trabalho de Coudry promove mudanças significativas no campo compreendido na interface entre a Linguística e as áreas de saúde e de educação. É nesse contexto que recorremos às ideias de Foucault $(2009,2011)$ sobre autoria, noção que pretendemos vincular à concepção de sujeito formulada pela ND, bem como ao tipo de acompanhamento realizado nos grupos de convivência e/ou nos atendimentos individuais - consequência dessa concepção de sujeito -, lugares de visibilidade de uma nova discursividade a respeito de patologias de ordem neurológica. Há uma marca, interpretada aqui como um modo particular de se dirigir e se referir aos sujeitos, instauradora de uma diferença fundamental nos estudos da linguagem no contexto patológico. A verificação dessa hipótese se faz por meio de um levantamento preliminar da escrita de casos na ND, a começar por aqueles relatados no livro Diário de Narciso, dos sujeitos N, P, e L. Iniciamos nossa reflexão nos reportando ao ambiente acadêmico, ao contexto das ideias linguísticas quando da produção da tese de doutorado de Coudry, com a finalidade de discorrer sobre os pressupostos teórico-metodológicos presentes na sua proposta. Em seguida, discutimos alguns episódios de interlocução entre terapeuta/investigadora e sujeitos afásicos, encontrados em artigos que versam a respeito das (in)capacidades discursivas de afásicos. Trazemos, ainda, trabalhos que se propuseram a refletir mais acuradamente sobre a escrita de caso na ND, a partir do acompanhamento de crianças autistas. Por fim, retomamos a discussão acerca da transmissão e da autoria no interior da ND. 
Em relação à questão da autoria no âmbito da ciência, é bastante conhecido o artigo "O que é um autor?", de 1969, do filósofo francês Michel Foucault, por tratar do que se propagou como sendo a "função-autor". Ao analisar as características da função-autor, uma das facetas da função-sujeito, Foucault remete ao modo do funcionamento da autoria nos discursos de algumas épocas e, especificamente no caso do discurso científico, ele afirma que na Idade Média os textos científicos eram identificados pelo nome do autor. Porém, nos séculos XVII e XVIII, ocorre uma mudança importante no sentido de uma inversão entre o discurso científico e o literário. Neste, a assinatura do autor passa a conferir legitimidade à obra, ao contrário do discurso científico, no qual vigora o apagamento do autor. De todo o modo, o filósofo não descarta os denominados "instauradores de discursos", como Freud, Marx, Nietzsche, ou seja, considera-os como fundadores de uma discursividade, enquanto o restante - qualquer outro -, seria propagador do que foi ouvido, falado e lido. Em outro texto de Foucault, "A ordem do discurso", publicado um ano depois, a dissolução do autor é retomada com um enfoque específico, já que a problemática de um enunciado pertencer ou não a determinado discurso vem analisada considerando as regras que passam a valer para que ele possa entrar naquele discurso. Está formulada a relação entre poder-discurso; nesse quadro, o autor importa como princípio de agrupamento, de unidade do texto e de coerência do discurso.

Como refletir sobre autoria no caso da ND considerando a elaboração de Foucault? É possível no discurso científico da nossa época atribuir ainda uma autoria a alguém? Considerando que, na atualidade, o que mais se verifica são agrupamentos de pesquisadores e de projetos ao redor de um tema, como fica a autoria? Se for possível, de qual natureza seria?

\section{A NEUROLINGUÍSTICA DISCURSIVA}

O número 42 dos Cadernos de Estudos Linguísticos, publicado em 2002, reúne artigos de diversos pesquisadores em torno do tema "História das Ideias Linguísticas", que traçam, cada um a seu modo e por um viés teórico-metodológico particular, momentos importantes do desenvolvimento da Linguística no Brasil. Um dos aspectos destacados na apresentação dessa coletânea pela sua organizadora, professora Eni Orlandi, diz respeito ao modo como esses pesquisadores realizam seu caminho na tradição da história das ideias no Brasil: eles são responsáveis pelo alcance, inclusive institucional, de articulações realizadas a respeito da língua - que se constitui, ao mesmo tempo, como o seu objeto de pesquisa e como o que os faz falantes. A característica comum a todos os autores, destacada por ela, é a capacidade de se interrogarem, e não só lançarem certezas, em relação à linguagem. O fato de o artigo da professora Maria Irma Hadler Coudry compor o Caderno "História das Ideias Linguísticas" mostra o reconhecimento de um projeto - uma Neurolinguística discursivamente orientada -, relevante pela dedicação aos estudos da fala/escrita de sujeitos acometidos (ou não) por lesões cerebrais. O objetivo do trabalho desenvolvido por Coudry é o de evidenciar os processos de significação (alternativos ou não) presentes em atividades de linguagem exercidas por sujeitos no contexto patológico. 
Como Coudry (2002, pp. 100-101) mesmo reitera, a ND, cuja sistematização deu-se a partir dos anos oitenta do século XX, torna-se possível em razão do desenvolvimento de princípios e de uma prática clínica bem distintos do que era reconhecido até então como "Neurolinguística", comumente vinculada aos campos da Neurologia e da Psicologia. O propósito dessa nova área de conhecimento foi o de mostrar como era necessária uma compreensão mais abrangente de linguagem, de língua e de sujeito - praticamente ausente do arcabouço da Neurolinguística tradicional - para, só assim, asseverar que há sujeito e há língua nas manifestações dos sujeitos afásicos.

Nesse sentido, é imprescindível trazer à cena a vinculação da autora à concepção teórica de linguagem postulada por Franchi: ${ }^{2}$ ela é de natureza indeterminada e também uma atividade constitutiva dos sujeitos. Ao exercê-la, em diferentes contextos culturais e sociais, os sujeitos realizam um trabalho com e sobre a linguagem, cuja significação, portanto, não é prévia, e sim construída.

Além disso, e justamente em virtude dessa concepção de linguagem, faz-se presente na ND o reconhecimento de outros estudos que incluíam o sujeito no escopo de sua investigação. Esse é o caso de pesquisas de neurologistas de meados do século XIX, antes de ocorrer o desenvolvimento da metodologia anátomo-clínica, ${ }^{3}$ como a do médico e afasiologista Lordat. Mesmo sem formação específica na área da linguagem, Lordat tratava o dado linguístico considerando as suas condições de produção, afastando-se de uma simples descrição das categorias gramaticais nele presentes, trazendo as dimensões da situação interativa, como quem o pronunciou, para quem e em que contexto foi produzido (Coudry, 1988, p. 39).

2 Diversos textos de Carlos Franchi são fundamentais para o desenvolvimento de uma nova perspectiva de abordagem da linguagem, francamente em oposição à teoria gerativista chomskyana, e, dentre eles, mencionamos o artigo intitulado "Linguagem - Atividade Constitutiva", de 1977.

3 Baseando-se em Hécaen e Lanteri-Laura (1977), Coudry (1988) explica o nascimento da metodologia anátomo-clínica como uma alternativa ao impedimento de se passar da experimentação animal para a patologia humana. Por essa metodologia são estabelecidas "comparações e correlações entre os sintomas observados durante a vida do paciente (no caso da afasia, a observação dos dados linguísticos) com fatores neuro-anatômicos inferidos de procedimentos clínicos ou obtidos postmortem." (p. 36). Como lembra a autora, muitos progressos foram alcançados na afasiologia clínica a partir desse momento, como a topografia das localizações cerebrais, a dominância hemisférica, entre outras propostas. Surgiram também as discussões, ao final do século XIX e início do XX, entre localizacionistas e anti-localizacionistas. É notável, de qualquer modo, como as avaliações diagnósticas de pacientes com afasia caminharam no sentido de nelas se incorporarem concepções de linguagem/ língua reducionistas, a de língua como código; por isso a eleição de atividades metalinguísticas e descontextualizadas nas tarefas solicitadas aos pacientes. 
Contribuíram ainda para a formulação de Coudry os trabalhos de renomados linguistas com interesse pelo inusitado da fala, como Jakobson ${ }^{4}$ e Benveniste. As obras de Jakobson trouxeram à luz a linguagem em funcionamento na fala de afásicos - por meio dos processos metafóricos e metonímicos -, por sua constatação do fato de que os distúrbios poderem ser preponderantemente da ordem da similaridade (metáfora) ou da contiguidade (metonímia), em nada diferente das (mesmas) leis as quais se encontram submetidas a linguagem de indivíduos sem lesão cerebral. A teoria da enunciação de Benveniste torna-se relevante nas formulações de Coudry $(1988,2002)$ em relação à interlocução. Ao trazer um dos pressupostos de Benveniste - de que sujeitos de uma comunidade "falam a outros que falam" (Benveniste, 1966, apud Coudry, 2002, p. 101), as condições de produção de um enunciado (quem e como enuncia, para quem se dirige, em que circunstâncias é produzido etc) estão incluídas na composição de seu sentido. Não só Benveniste abordou o discurso, mas também o seu antecessor, Saussure (2004), cuja afirmação a respeito da relação língua-discurso merece ser considerada, no sentido de o fundador da Linguística Moderna ter alçado a fala e o falante como essenciais ao funcionamento da língua, apesar de seus críticos dizerem o contrário. De acordo com Saussure (2004, p. 237), “A língua só é criada em vista do discurso... [...]...a língua realiza, anteriormente, apenas conceitos isolados, que esperam ser postos em relação entre si para que haja significação do pensamento". 5

3/ Jakobson foi quem lançou o termo estruturalismo no campo das ciências, seguindo o lastro deixado por Saussure (2006). É importante salientar o quanto seus estudos foram muito além daquilo comumente atribuído a um linguista. Nas palavras de De Lemos (2014, p. 957), ele "almejava dar conta de um objeto com falhas e, por isso, incluiu no escopo de suas atividades de linguista não só a fala da criança, mas também o balbucio, a afasia e a poesia". Em relação aos estudos afasiológicos, lembramos que, ao reconhecer os avanços empreitados por neurologistas como Goldstein, Luria e Ombredane, por fazerem uso da literatura linguística básica, Jakobson (1973, p. 46) não deixa de mencionar que "qualquer variedade de afasia, qualquer caso individual oferece um material linguístico bastante complexo e intricado, o qual não pode ser satisfatoriamente analisado sem a colaboração de um linguista equipado com todos os meios técnicos e métodos da moderna ciência da linguagem" (grifos nossos).

5 Acreditamos que esse postulado deva ser compreendido a partir da noção de língua como um sistema de valores que "conhece somente sua ordem própria" (Saussure, 2006, p. 31) e, concomitantemente, considerando o funcionamento intrincado das relações sintagmáticas e associativas: o encadeamento ou a articulação entre termos por uma relação de oposição entre um termo e o seu antecedente, assim como o seu sucessivo (relação sintagmática) - uma retroarticulação imprescindível para que haja significação -, ao mesmo tempo em que cada palavra dessa cadeia "fará surgir inconscientemente no espírito uma porção de outras palavras...[...]." (p. 143), ou seja, palavras latentes depositadas no "tesouro interior que constitui a língua de cada indivíduo" (p. 143) e que podem ser associadas ao termo alvo (relação associativa). Lembremos ainda que "discurso" foi empregado por Saussure como sinônimo de "fala", como um encadeamento posto em funcionamento pelo falante. Não se trata, portanto, de uma concepção de discurso tal como é concebida, por exemplo, pela Análise do Discurso Francesa. Acreditamos que Saussure não tenha ignorado o falante na sua teorização a respeito da língua, tanto que é possível encontrar discussões a respeito do sujeito-falante e da Linguística da Fala nos textos atribuídos a ele (os compilados por seus alunos, os próprios manuscritos, as cartas etc). 
Uma outra perspectiva teórica permitiu à Coudry incluir no escopo de seu trabalho o acompanhamento longitudinal de sujeitos afásicos. ${ }^{6}$ Do interacionismo em Aquisição da Linguagem veio a possibilidade de ela poder se interrogar a respeito da dialogia. Ao mencionar o Projeto de Aquisição da Linguagem, ${ }^{7}$ a autora deixa claro o impacto positivo do contato com uma teoria que incluía as manifestações de sujeitos, no caso a fala de crianças, nas suas elaborações teóricas. Nesse sentido, o diálogo nos processos interativos entre investigador-afásico passa a ser considerado fundamental na constituição da significação. Para De Lemos (1981, 2002), o diálogo é uma unidade teórico-metodológica de análise, no qual se privilegia a relação estrutural entre a fala da criança e a do seu interlocutor. Veremos mais adiante as consequências dessa assunção para a ND por meio da análise de episódios entre criança-investigador.

6 O título do livro de Coudry (1988), Diário de Narciso: discurso e afasia, remete ao primeiro sujeito afásico acompanhado por ela. Ao explicar o título de sua tese de doutorado, a autora faz referência ao mito de Narciso, chamando atenção, porém, para o fato de o sujeito acometido pela afasia ter o reconhecimento de si mesmo em diversas situações interativas em que é instado a se expressar. Mais ainda, ele teria um estranhamento de si mesmo. Pode-se falar em um sofrimento decorrente dessa nova condição subjetiva. Nesse sentido, deve-se reconhecer como essencial a troca de experiências entre afásicos e também com não-afásicos que ocorre no Centro de Convivência de Afásicos (CCA). Criado em 1989, esse Centro, como descreve Coudry (2014, p. 3491) "funciona no Instituto de Estudos da Linguagem (IEL) e é fruto de um convênio interdisciplinar do Departamento de Linguística com o Departamento de Neurologia da Faculdade de Ciências Médicas da Universidade Estadual de Campinas. É um lugar em que sujeitos afásicos e não afásicos participam de um ambiente de linguagem (fala, leitura e escrita) em que como interlocutores (de afásicos e de não afásicos) constroem e partilham de vários interesses, papéis e conhecimentos que os identificam como falantes de uma língua natural; um ambiente em que acontecem as mais diversas atividades linguageiras, carregadas de marcas particulares e de dizeres/escritos partilhados pela comunidade de fala (Sampaio, 2006) que caracteriza o grupo".

7 O Projeto de Aquisição da Linguagem da Unicamp foi proposto por Cláudia T. G. de Lemos, em 1976, e coordenado por ela até o final dos anos 90 (Lier-De Vitto; Carvalho, 2008). 
Pressupostos teóricos de linguistas e neurologistas afinados com uma concepção de língua, linguagem e sujeito bem mais ampla e rigorosa do que aquela comumente encontrada nos estudos neurolinguísticos vigentes, permitiu, enfim, ir além de uma avaliação de linguagem baseada em testes padronizados. O incômodo de Coudry com os protocolos de avaliação estandardizados vinha, acreditamos, do seu compromisso com o sujeito afásico. Isso a fez buscar na Linguística as bases para a constituição de uma abordagem teórico-metodológica de avaliação e de acompanhamento dos sujeitos com as denominadas alterações de linguagem. ${ }^{8}$ A rotina de trabalho nos grupos de convivência e, também, nos atendimentos individuais foi e continua sendo pautada pela realização de atividades discursivas mobilizadoras de diferentes funções linguístico-cognitivas (Coudry, 1999; Possenti, 2002, entre outros autores). Numerosas estratégias para o exercício da linguagem na interlocução - uso da agenda, do jornal, do álbum de fotos, do caderno de atividades, entre outras - são consideradas produtivas por contemplarem diferentes dimensões do discurso, como a metaenunciativa (relatos, contar ou interpretar uma piada etc), a interlocutiva (assumir os diversos papeis) e a discursiva (julgamentos em relação a situações vistas ou vivenciadas). Nessas situações de exercício da linguagem, como nos lembra Coudry (1999, entre outros), esses sujeitos frequentemente encontram dificuldades, e, por isso, a importância de que a interpretação do investigador seja teoricamente orientada, pois, só assim, é possível a (re)condução do processo de subjetivação desses sujeitos.

Mesmo sabendo da impossibilidade de reunir as incontáveis contribuições da ND no espaço deste artigo, daremos visibilidade aos seus efeitos na clínica, particularmente na de linguagem, como procuraremos indicar na próxima seção. Constatamos, por exemplo, a ocorrência de mudanças - ética inclusive - na postura terapêutica dos fonoaudiólogos que ingressaram para realizar seus mestrados e/ ou doutorados na área da ND do Departamento de Linguística da Unicamp. Esses profissionais foram afetados por uma concepção teórico-metodológica centrada na indeterminação da linguagem e na realização de um trabalho linguístico dos sujeitos envolvidos na interlocução. As baterias de testes que se interpunham na relação com o sujeito afásico ou com um outro sujeito "portador" de um rótulo neurológico mais "prestigiado" foram deixadas de lado, depois de terem passado por uma análise crítica do ponto de vista linguístico-discursivo, o que não quer dizer, ressaltamos, a ausência de protocolos avaliativos voltados ao discurso.

8 Além da afasia, outras alterações em que a relação sujeito-linguagem está afetada e causa sofrimento e desconforto, seja ao seu interlocutor seja a si mesmo, vêm sendo investigadas por Coudry, dentre elas a demência e a síndrome frontal (Coudry, 1992). Mais recentemente, crianças e jovens que recebem diagnósticos neurológicos - dislexia, alteração do processamento auditivo, dificuldade de aprendizagem, transtorno de déficit de atenção com ou sem hiperatividade, deficiência mental - os quais "produzem efeitos negativos em seu processo de escolarização e em sua vida" (Coudry, 2014, 3491), vêm sendo acompanhados no Centro de Convivência de Linguagens - o CCazinho (IEL/Unicamp) -, iniciado em 2004 por Coudry, cujos princípios teórico-metodológicos são os mesmos que fundamentam o CCA. 
O compromisso, como já mencionado, passa a ser com o sujeito que se encontra em uma condição subjetiva de "desconforto e sofrimento" (Coudry, 2002, p. 101). Nesse sentido, é fundamental o papel do outro como intérprete das manifestações desse sujeito, ou seja, de um outro que não pode prescindir de responder (mesmo que seja com o silêncio). A diferença em relação a uma outra situação interlocutiva cotidiana vem do fato de o terapeuta não poder se abster da sua formação teórica - mergulhado na problemática do sujeito, da língua e da linguagem - na relação com esse sujeito. O terapeuta visa a empreender mudanças linguísticas nesse sujeito, mesmo não tendo controle dos efeitos de sua fala e de suas ações - como de fato ocorre em qualquer situação interativa. É o ato linguístico de sua parte que faz diferença: ao realizar um ato linguístico, no sentido de vir a ser provocador de mudanças na linguagem do sujeito, o terapeuta está imbuído tanto por concepções teóricas que o orientam quanto pela relação de confiança por parte do paciente, e é isso que lhe permite organizar práticas discursivas ${ }^{9}$ pertinentes para cada caso e para o coletivo dos sujeitos.

Mais algumas palavras em relação ao artigo de 2002 de Coudry, dessa vez correlacionando proposições ali presentes ao conceito de função-autor, tal como vem brevemente referido no texto $A$ ordem do discurso, de Foucault. Considerado como um dos três procedimentos internos de exclusão do discurso - ao lado do comentário e da organização das disciplinas -, o autor seria um princípio de organização do discurso, como unidade e origem de suas significações. Estamos diante de uma visão negativa da função-autor por parte de Foucault, já que visto dentro do critério de exclusão de um determinado discurso. O exemplo fornecido pelo filósofo para a discussão dessa função é o de Mendel, o qual foi banido à época por não estar "no verdadeiro" do discurso biológico, pelo fato de não seguir as regras de formação dos objetos e dos conceitos desse campo de conhecimento. No entanto, as teses desse autor vieram a ser aceitas posteriormente pelo discurso biológico, a partir de mudanças de escala e de objetos dentro dessa ciência, como adverte Foucault.

Nesse sentido, situamos a empreitada teórico-metodológica de Coudry como uma forma de resistência ao discurso hegemônico da medicina em relação às patologias da linguagem. No caso das afasias, Coudry lançou questões e dúvidas a respeito das avaliações cognitivo-linguísticas realizadas com os sujeitos, já que nelas não se levava em conta, de fato, a linguagem em funcionamento em todos os seus aspectos (na relação entre os níveis linguísticos e nos parâmetros antro-culturais envolvidos). A atribuição de autoria à Coudry vem do fato de seu trabalho possibilitar a ruptura com a noção generalizada de não haver mais sujeito na afasia, com a "cegueira" generalizada à ocorrência dos processos alternativos de significação por parte dos sujeitos afásicos nas situações concretas de interlocução.

9 "Prática discursiva (...) envolve a reversibilidade essencial entre as duas faces do discurso, a textual (verbal) e a social, e em cujo trânsito se dá a relação de língua com a cultura, do sujeito com o outro e o mundo social" (Maingueneau, 1989, p. 60). 
As dúvidas postas por Coudry em relação à avaliação e à terapia dos processos linguístico-cognitivos de sujeitos afásicos praticadas no âmbito da medicina e áreas correlatas denotam justamente esse momento de cisão com um discurso considerado "verdadeiro" a respeito da afasia. São os relatos dos acompanhamentos longitudinais de sujeitos afásicos que possibilitaram essa virada no discurso: de centrado na patologia para um olhar para o sujeito. Voltemo-nos, então, para a escrita de caso na Neurolinguística Discursiva e sua real possibilidade de interrogar o clínico, o investigador e o leitor.

\section{A ESCRITA DE CASO NA AFASIA}

No prefácio do livro Diário de Narciso: discurso e afasia, Carlos Franchi, o orientador da tese de Coudry, afirma que ela "não consegue "esconder a convivência afetiva e pessoal" com os seus sujeitos N, P, L" (p. XIII). Sabemos, ao ler o livro, que esses dizeres são verdadeiros e implicam também uma rigorosa reflexão teórica a respeito da avaliação de linguagem dos afásicos e da direção do acompanhamento empreendido. Destacando, um a um, os testes das avaliações tradicionais usados na área da afasiologia, e comprovando a sua ineficiência em razão das concepções estreitas de língua, linguagem e sujeito que as guiam, a autora relata alguns casos, não como exemplos de teorias a respeito dos tipos de afasia, mas como uma narração dos atendimentos realizados. O objetivo é de suscitar nos leitores uma reflexão sobre os sujeitos afásicos e suas dificuldades e, também, sobre as noções de linguagem, língua e sujeito envolvidas.

No processo terapêutico de $\mathrm{P}$, o propósito foi estabelecer com ele diálogos e narrativas cada vez mais complexos. Vejamos: nos diálogos, P "se serve de "nominalizações" da ação em vez de nomes de participantes ou objetos" (Coudry, 1988, p. 104), como no enunciado produzido por ele na situação de ver fotos de jogadores de futebol atuando em campo. Ao ser instigado a responder o que eles faziam, P afirmou "Jogas". Em outra situação, quando viu a foto de uma moça telefonando e foi indagado a respeito do que ela estava fazendo, ele disse "Telefone". As construções "fragmentárias" de P estariam indicando "problemas em estruturar orações por dificuldade de expressar, mediante um verbo, a ação ou processo e, pois, as relações entre os participantes e objetos nessa ação ou processo" (Coudry, 1988, p. 106). Contudo, durante o processo terapêutico ocorreu "o desenvolvimento, por parte de $\mathrm{P}$, de uma estratégia para contornar essa dificuldade: a explicitação de um desses participantes ou objetos que seja específico da ação esperada como resposta" (idem, p. 107). Uma das atitudes adotadas por Coudry no diálogo com $\mathrm{P}$ foi a de insistir na reelaboração da resposta dada por ele, como acontece no episódio em que ele respondeu "Lojas"; ela retoma a pergunta enfatizando o acento frásico sobre a ação ("O que tão fazendo essas pessoas?"), e ele fala "Vitrinea [...], bolsa, biquíni." (ibidem, p. 116). De acordo com Coudry, não se trata simplesmente de uma "correção" por tentativas, mas um processo de trabalho linguístico consciente - trazer mais especificadores da ação - por parte do sujeito. 
No acompanhamento de $\mathrm{N}$, é nítida a presença na sua fala de fragmentos da fala do outro. Ele aderia à fala de seu interlocutor para, só depois, passar a uma resposta mais efetiva, como na situação em que, ao ser indagado sobre suas dificuldades, "A maioria das coisas o senhor consegue falar?", ele responde "Consegue, consegue, consigo". ${ }^{10} \mathrm{Um}$ dos recursos alternativos para se manter no diálogo e na narrativa, evitando sua ruptura, foi o de solicitar um prompting por parte do seu interlocutor, assim como acompanhar com gestos representativos aquilo que ele queria dizer.

No caso de L, as suas dificuldades não eram tanto sintáticas ou semânticas, mas preponderantemente discursivas. Em diversas situações dialógicas, L exercia o papel de locutor, mas não considerava as intervenções propostas por seu interlocutor, chegando a sobrepor sua fala à dele, como no episódio em que, ao ser questionado se lia jornal, ele responde "Lia normal, todos os dias", e na continuidade, quando a investigadora lhe pergunta se "Revista também o senhor lia?, ele sobrepõe ao segmento "também o senhor lia?" o enunciado "Todos os dias lia jornal." L conseguiu expressar sua dificuldade de acompanhar aquilo que era dito por seu interlocutor, ao emitir seu testemunho: quando ouvia notícias na TV dizia se sentir excluído, "a ponto de indicar uma falta de sintonia entre o que é dito e o que pode acompanhar do que é dito: "num consono a voz junto com eles"” (idem, p. 190). Uma estratégia para enfrentar essa problemática foi sendo construída a partir da observação de quais seriam os recursos que estariam possibilitando a compreensão dos diálogos dos quais ele participava. Dentre eles, pareceu evidente a necessidade de seus interlocutores utilizarem os gestos e a escrita, além da fala.

Discutiremos brevemente outros dois episódios, reportados respectivamente por Possenti (2002) e por Coudry (1999), nos quais a questão da competência discursiva está posta em discussão, assim como a interpretação de falas/textos por parte do terapeuta e do investigador. No primeiro texto, o enunciado de um sujeito e suas condições de produção são analisados, o que já ocorrera em um outro artigo do autor, de 1991, em coautoria com Coudry. Trata-se de segmentos do acompanhamento do sujeito AF, descrito como alguém com dificuldades para lidar com a heterogeneidade da linguagem, com os aspectos da polissemia e da inferência. No entanto, mudanças nesse quadro puderam ser observadas e isso ocorreu, em parte, por sua participação no CCA e no acompanhamento individual, ou seja, em razão de ele estar envolvido em atividades orientadas para o discurso, em que diversas possibilidades de significação

$1^{0}$ Do ponto de vista da ND, essa seria uma atividade epilinguística realizada pelo sujeito, compreendida como ocorrendo quando o sujeito opera sobre a própria linguagem, comparando, transformando e experimentando outra forma de dizer o que pretendia (Franchi, 1987).

$1^{1} \mathrm{O}$ conceito de heterogeneidade é entendido como a presença do outro - de maneira explícita ou não - na linearidade da frase ou do discurso daquele que enuncia (Authier-Revuz, 2004, p. 12). São dois tipos de heterogeneidade, a constitutiva ("o outro no um") e a mostrada ("das outras palavras, sob as palavras, nas palavras", como no caso da polissemia, da homonímia.). Importante destacar como esse conceito aparece em outras áreas. Para a perspectiva interacionista em Aquisição da Linguagem, a fala da criança é considerada heterogênea e imprevisível. A heterogeneidade vem do fato da presença de fragmentos incorporados do outro nessa fala, ou seja, "pedaços" da fala do outro não analisados pela criança. Não esquecendo que dessa incorporação aparecem os "erros", imprevisíveis e instáveis (Lier-De Vitto; Carvalho, 2008, grifos nossos). 
da linguagem foram inseridas. Vejamos: AF contara, ao final de uma sessão, que estava tentando voltar a trabalhar, ocasião em que lhe foi perguntado a respeito do que estava fazendo "agora". Ele deu um sorriso malicioso e respondeu? "Agora? Agora estou falando com o senhor". Ambos - o sorriso e a resposta verbal de AF - foram interpretados (Possenti; Coudry, 1991) como uma mudança de posição subjetiva na relação do sujeito com a língua e com o outro.

O segundo episódio ou um dado-achado, ${ }^{12}$ foi trazido por Coudry (1999). É de uma situação em que GC, um afásico "fluente", fora instado a interpretar uma charge. GC apresentava dificuldades de se colocar no lugar do outro, comentar a respeito do seu dizer ou do dizer do outro, o que restringia suas possibilidades interpretativas. A charge mostrada a ele tinha o título de "Greve dos petroleiros" (FSP, 1995). $\mathrm{Na}$ imagem aparecia uma mulher esperando o marido com um rolo de macarrão encostada na parede ao lado da porta (aberta) de entrada da casa. Em primeiro plano, vê-se a boca de um fogão com teias de aranha e, ao fundo, quase em cima da soleira da porta, o marido empunhando um cartaz no qual está escrito "GREVE". GC ficou em silêncio e demorou para falar. As perguntas feitas pelo investigador ${ }^{13}$ giraram em torno dos elementos pré-construídos, com o objetivo de reestabelecer, como já comentamos, uma competência (inter)discursiva: "o que está escrito nessa tabuleta?... [...] a mulher tá brava ou não? Por que ela tá brava? Que que tem em cima dessa boca de fogão?...[...]" (Coudry, 1991, p. 153). À questão "Por que ela tá brava?" GC respondeu "que o marido chegou fora de hora", uma assertiva insuficiente para a interpretação da charge, mas, sabiamente plausível em outra formação discursiva (a mulher fica brava quando o marido chega tarde em casa). Interessante notar que, na análise de Coudry (1999), os esforços dessa construção conjunta da significação passam pelo reconhecimento, por parte do investigador, ${ }^{14}$ de que GC deixou de ocupar lugares enunciativos, tanto que não houve possibilidade de ele compreender, naquela circunstância específica, o texto como uma charge política. No entanto, o investigador faz essa transposição, coloca-se no lugar dele (do outro) e procura acompanhar os possíveis caminhos de trilhamento da linguagem daquele sujeito - retraçando os interdiscursos - para compor a significação do que estava sendo lido.

$1^{2}$ De acordo com Coudry (1996), o dado-achado resulta da relação recíproca entre teoria e dado, indicando um processo em andamento, e só reconhecido por conta de um olhar/escuta teórica do investigador. O dado-achado permite não só observar o processo em curso no próprio sujeito, mas também fornece impulso para a própria teoria.

$1^{3}$ Importante mencionar, como parte do desenvolvimento da ND, a criação do Banco de Dados em Neurolinguística (BDN), um arquivo em que se encontram transcritas as sessões, e a partir do qual é possível selecionar e analisar algum aspecto linguístico-discursivo da linguagem de determinado sujeito. $\mathrm{O}$ BDN segue formas de registro que procuram, na medida do possível, ser fidedignas ao que ocorreu nas sessões, tanto de grupo quanto individuais. Nessa transcrição, há espaços para o registro da fala e dos gestos realizados pelos interlocutores e das condições de produção dessas manifestações.

$1^{4}$ No âmbito da perspectiva interacionista, Carvalho (2006, entre outros) faz uma reflexão em torno da posição do investigador face ao dado de fala da criança. Para a autora, quando o investigador, ao ler e reler as transcrições das situações de interação criança-adulto, se surpreende com uma fala da criança, em razão de uma combinatória singular de significantes - o "erro", por exemplo - ele não deveria se basear na interpretação dada pelo adulto naquele diálogo, mas, sim, deixar-se submeter à diferença/impasse que a fala da criança representa e, concomitantemente, se incluir, no sentido de que algo da sua própria fala - já esquecida, recalcada (De Lemos, 2014, p. 961) - retorna. 
Retomando o conceito de "autoria" de Foucault, central neste artigo, "o lugar vazio do autor" não é suficiente se não se buscam as condições de funcionamento de práticas discursivas específicas. No caso da ND, por meio da expressividade da obra inaugural Diário de Narciso, houve a instalação de uma nova discursividade no campo das patologias na/da linguagem, como já apresentado. Os conceitos criados e os métodos propostos formam um conjunto bem delimitado e recorrente nos textos de Coudry. A esse "passo a mais", capaz de inaugurar uma nova discursividade, foi decisivo tanto o ambiente acadêmico e de pesquisa no qual Coudry estava inserida quanto a sua sensibilidade à linguagem dos afásicos e aos acompanhamentos terapêuticos deficitários a que eles estavam submetidos. Como assevera Foucault (2001), os autores não são somente os autores de suas obras, mas eles abrem "a possibilidade e a regra de formação de outros textos" (Foucault, 2001, p. 284), no sentido de que um autor permite tanto um certo número de analogias quanto um certo número de diferenças (idem, p. 285) no interior mesmo de determinado discurso. Essa reflexão nos remete ao conceito de "transmissão".

\section{A ESCRITA DE CASO NO AUTISMO}

As duas pesquisas apresentadas a seguir - que tratam do acompanhamento terapêutico fonoaudiológico de crianças com o diagnóstico neurológico de autismo - representam leituras distintas propiciadas a partir da obra inaugural da ND, mas que devem ser tomadas no interior dessa discursividade.

Comecemos pelo trabalho de Bordin (2006), que relata o acompanhamento fonoaudiológico realizado por ela, de um menino com o diagnóstico de autismo. Já no início de sua reflexão sobre a linguagem do garoto LJ, a autora narra a tendência dela mesma (na posição de terapeuta) ter dificuldade para entender a fala dessa criança, por não se enquadrar na prosódia e no ritmo da língua portuguesa. Para Bordin, surge a dúvida em relação ao modo como esta criança escutava a língua que vem do outro. Como escutar algo dessa fala e, assim, permanecer na interlocução com essa criança? A autora encontra na ND um lugar para refletir sobre esse acontecimento inquietante da clínica.

Recorrendo a um postulado de Freud neurologista - período de sua publicação compreendido entre os anos de 1891 e 1895 - de que em condições adversas o aparelho de linguagem/memória pode não funcionar plenamente e, trazendo essa concepção para a clínica na qual atua, Bordin considera ser possível dizer de uma afetação, em razão da presença de condições adversas, nos outros funcionamentos ${ }^{15}$ - do motor, do perceptual, do pensamento e da estruturação psíquica.

$1^{5}$ A relação cérebro-linguagem na ND também é trazida a partir das postulações de Luria (1979, apud Coudry; Freire, 2005) - influenciado, por sua vez, pelas ideias de L. S. Vygotsky. O funcionamento dinâmico do cérebro, com suas principais estruturas e funções - descrito como hierárquico, coordenado e integral -, sustenta a aprendizagem humana, a qual é construída na relação com outros homens e com a cultura, historicamente contextualizada (pp. 26-27). 
O acompanhamento de LJ torna-se complexo por exigir do terapeuta se defrontar com uma questão enigmática: “como LJ habita a linguagem?” (Bordin, 2006, p. 16). Essa pergunta ecoou por muitos anos, ao longo do processo terapêutico instaurado com essa criança, e percorreu também a elaboração do próprio texto produzido por Bordin. A pesquisadora traz uma fala de LJ que tinha a extensão de um enunciado, mas não compreendida por ela. Isso a interrogou por muitas outras sessões, até que, ao colocá-la em uma cadeia textual-discursiva, esse segmento ganhou, ousamos dizer, "determinação semântica e textual, escapando da homonímia e deriva, (o) que lhe dá estatuto fonológico, morfológico e sintático (...)." (De Lemos, 1995, apud Carvalho, 2006, p. 75). Houve um reconhecimento de sua parte de que, naquele momento, ela mesma tinha passado a explicar a fala de LJ considerando-a a partir da sintomatologia do autismo, das descrições de comportamento e da linguagem do autista - sempre deficiente -, tão presente na literatura médica e fonoaudiológica, constituindo-se como uma barreira para sua aproximação da criança. Nesse sentido, reconhece que a ND fez diferença na sua formação teórica e atuação clínica, pois com ela e por ela foi possível eleger para si a relação sujeito-linguagem e não somente a patologia.

À pergunta inicial do seu trabalho, “como LJ habita a linguagem?”, a autora alega não ser possível oferecer uma resposta conclusiva, mas indica alguns caminhos, como o fato de ele não se apresentar todo o tempo com uma fala sintomática. A incidência da fala/silêncio do terapeuta - a partir de uma escuta teoricamente dirigida - pôde movimentar a significação (ou a falta dela) em diversas direções, sempre na tentativa de fazer com que LJ tivesse uma fala/voz própria.

Na elaboração de Perottino (2009) a respeito do atendimento de uma criança, JM, também diagnosticada como autista, são reportados os efeitos dos pressupostos teórico-metodológicos da ND no acompanhamento fonoaudiológico realizado. Uma das discussões postas nesse trabalho é a escrita de caso. Tendo por base a escrita dos casos de N, P, L realizada por Coudry (1988), mais as contribuições acerca do tema advindas de outras áreas, como as da psicanálise (Nasio, 2001, Leite, 2006), entre outras, a reflexão é aprofundada por Perottino em outro texto, de 2011, e versa a respeito da necessidade de escrever um caso. De acordo com o seu ponto de vista: "A escrita de caso diz respeito ao paciente e ao clínico, desse encontro que resulta em algum tipo de mudança de uma condição prévia, tanto por parte do terapeuta quanto do paciente" (Perottino, 2011, p. 583). Mudança implica em movimento e, no caso do paciente, seria esperado que ele deixasse a condição de sofrimento e, no caso do terapeuta, houvesse uma provocação em relação à "segurança" e às certezas do seu saber clínico. Para Nasio (2001), a escrita de caso seria uma ficção, pois nela observa-se uma recriação do ocorrido em cena, não sendo o acontecimento mesmo, naquele tempo e lugar. Mas, tanto para Nasio, quanto para Leite (2006), a escrita seria um dos lugares circunscritos da transmissão, como é possível de se verificar "na produção do analisante no tratamento, na supervisão (controle), no ensino, nas publicações etc..." (Leite, 2006). Em outros termos, a transmissão faz avançar o saber teórico, o qual passa a ser suspenso diante do encontro com um novo paciente. 
Trazemos um pequeno excerto do acompanhamento fonoaudiológico de JM, transcrito e analisado por Perottino (2011), cuja indagação acaba sendo semelhante àquela feita por Bordin (2006) em relação à escuta da terapeuta durante a sessão. Trata-se de uma situação em que o paciente, então com 3 anos e 6 meses, e a terapeuta estão vendo um livro ilustrado de meios de transporte: ora a terapeuta indaga sobre a figura, "o que é?", ora a terapeuta comenta a respeito da figura, "olha, o ônibus tá levando as pessoas para casa". Ao virar uma das páginas do livro, deparam-se com a figura de um trem e a criança produz "quéim", seguida imediatamente pela produção da terapeuta, "trem". Ela continua o diálogo comentando a respeito de uma luz/farol do trem, dizendo "Acendeu, a luz. Acendeu" (prolongando a vogal "A" nas duas produções da palavra acendeu), ao mesmo tempo em que faz com as mãos à sua frente o movimento repetitivo de abrir e fechar os dedos. Logo em seguida, JM fala "Qué mom. A::" (com o A prolongado). Nesse enunciado, aparece o fragmento de um texto ausente, que diz respeito a uma situação em que a terapeuta lhe contava a história de duas crianças que se vestiam de monstros e brincavam de assustar pessoas, com base no livro "Zuza e Arquimedes", de Eva Funari. Em várias passagens da história, a terapeuta dizia "Dois monstros", a partir da leitura da imagem de duas crianças que estavam fantasiadas e que saíam do baú e assustavam quem passasse por perto. Esse enunciado, referente à figura das duas personagens saindo do baú, era acompanhado pelo gesto de abrir e fechar os dedos da mão em frente ao corpo.

A fala de JM, "Qué mom. A::", que se seguiu aos gestos e à fala da terapeuta na situação de ver o livro de meios de transporte, é reveladora de um deslizamento metonímico: o gesto ou, então, o "a" prolongado de "Ácendeu", produzido pela terapeuta, evocou "mom"-, isto é, fragmentos do texto presente naquela situação ("A::ssustou" - quando os "monstros" saem do baú). Do ponto de vista de Perottino (2011, p. 589), esse enunciado "Qué mom. A::", não escutado pela terapeuta na cena, mas somente depois, quando houve a leitura e releitura das transcrições das sessões, aponta para uma relação entre significantes: eles vêm do outro, e dizem respeito ao funcionamento da língua e a um processo de subjetivação comandado pela língua, ou seja, "aponta para um sujeito emergente no intervalo entre significantes do outro" (De Lemos, 2002, p. 58 , grifos da autora). Cabe ressaltar que esse enunciado retornou posteriormente na fala de JM em outras ocasiões, em início de sessões, por exemplo, e passou a significar, então, como um pedido para a terapeuta contar a história de "Zuza e Arquimedes".

O enunciado produzido pela criança gera sempre efeitos no outro/ na terapeuta. Eles são variáveis, assim como a fala de criança não é sempre a mesma: o que a criança produz pode ou não ser escutado de imediato, ou lançar um desafio, uma "procura" por outros enunciados da língua que possam conferir sentido, forma e intenção àquela fala sintomática, a princípio, sem uma ancoragem. 
Não há nada premeditado, controlado ou garantido, como seria o caso de categorias linguísticas a priori ou de intenções comunicativas transparentes, nas falas, sejam elas sintomáticas ou não, pois a significação vai se produzindo na situação de interação paciente-terapeuta, em práticas discursivas significativas e na relação de confiança/transferência estabelecida entre os dois A necessidade de escrever um caso vem do fato de encontro paciente-terapeuta ter sido provocador de mudanças na linguagem do paciente e, do lado do terapeuta, ter possibilitado transformar o seu saber teórico. Escrever o caso também é uma forma de transmissão e isso se concretiza se o efeito da elaboração do caso for também o de mudança para aquele que o lê.

Retomando a questão posta antes do relato dessas duas pesquisas realizadas no âmbito da ND: é possível dizer que a ruptura do discurso médico a respeito de patologias da linguagem presente no trabalho de Coudry, ao interrogar e duvidar das chamadas "verdades" de um campo discursivo - como nos lembra Foucault (2009) a respeito de instauradores de novos discursos - inaugura uma nova

forma de pensamento sobre a patologia e produz efeitos. É ponto pacífico que a transmissão desse novo discurso vem dos expedientes científicos - publicações, ensino, escrita de casos -, mas ele só passa a fazer sentido quando ocorre uma provocação para aquele que lê ou escuta, quando tem efeito de sentido de verdade para esse sujeito.

\section{CONSIDERAÇÕES FINAIS}

Retomamos os postulados de Franchi (1977), quais sejam, a indeterminação da linguagem e a construção das categorias linguísticas na situação de interação, para que possamos afirmar que a ND se constituiu a partir desse contexto epistemológico. Coudry tornou produtivo cada um desses conceitos nos encontros com os sujeitos afásicos, seja nos grupos de convivência ou no acompanhamento individual. É digno de nota o fato de haver um contexto institucional propício - o Departamento de Linguística (IEL/UNICAMP) -, constituindo-se como incentivador e propagador de pesquisas realizadas por seus docentes, o que consideramos como um fator relevante na circulação dessa nova discursividade.

No presente artigo, os relatos de casos, presentes nos escritos da ND, e apresentados de forma resumida na penúltima sessão deste texto, confirmam a realização de um trabalho árduo com e sobre a linguagem por parte dos sujeitos envolvidos na interação.

Os efeitos na linguagem dos sujeitos, afásicos ou autistas, na situação de interlocução, não são previsíveis, como diversas análises de dados na ND indicam. No entanto, isso não quer dizer deixar de lado a necessidade de o investigador e o terapeuta terem um olhar e uma escuta - teoricamente orientados -, para o sujeito na sua relação com a língua, pois são somente atos linguísticos que podem provocar mudanças nessa relação sujeito-língua. 
O deixar-se tocar pelo outro - pelo seu desconforto e pelo sofrimento - foi crucial para a inauguração da proposta da ND no interior da Linguística, e os seus reflexos em outras áreas, como na Neurologia, na Educação e na Fonoaudiologia, sabemos, ainda estão por ser construídos. O traço principal do projeto teóricoprático da ND é o de desmistificar a patologização de sujeitos nos diferentes contextos institucionais. Consideramos que essa seja a (sua) marca fundamental na transmissão ao outro. O sentido dessa transmissão também se realiza, necessário lembrar, na transformação ou reformulação da teoria no encontro com o outro/ paciente e quando se escreve o caso.

A atribuição de autoria à Coudry, e a consequente transmissão da ND, decorre do modo particular e singular - sempre teoricamente guiado - de se relacionar com os sujeitos no contexto patológico. Isso pode ser atestado nos relatos dos pequenos grandes casos escritos por ela e, também, por quem compartilha e avança/provoca suas formulações. São também os sujeitos - como os ainda afásicos, mas já mais discursivos -, os que ganham com o saber-querer-fazer dessa autora.

\section{$\overline{\text { REFERÊNCIAS BIBLIOGRÁFICAS }}$}

AUTHIER-REVUZ, J. Heterogeneidade mostrada e heterogeneidade constitutiva: elementos para uma abordagem do outro no discurso. Entre a transparência e a opacidade: um estudo enunciativo do sentido. Porto Alegre: EDIPUCRS, pp. 11-80, 2004.

BORDIN, S. M. S. Fale com ele: um estudo neurolinguístico do autismo. Campinas, 2006. 129 f. Dissertação (Mestrado em Linguística) - Instituto de Estudos da Linguagem, Universidade de Campinas.

CARVAlHO, G. M. O erro em aquisição da linguagem: um impasse. In: LIER-DE VITTO, M. F.; ARANTES, L. (Org.) Aquisição, patologias e clínica de linguagem. São Paulo: Educ, pp. 63-78, 2006.

COUDRY, M. I. H. Diário de Narciso: discurso e afasia. São Paulo: Martins Fontes, 1988 [1986].

COUDRY, M. I. H. Fontes e postulados discursivos no estudo da afasia. Cadernos de Estudos Linguísticos, Campinas, n. 22, pp. 167-171, 1992.

COUDRY, M. I. H. O que é dado em Neurolinguística? In: CASTRO, M. F. P. (org.) O método e o dado no estudo da linguagem. Campinas: Editora da Unicamp, pp. 179-192, 1996.

COUDRY, M. I. H. Processos de subjetivação e trabalho linguístico. Estudos Linguísticos, XXVIII, pp. 151-155, 1999.

COUDRY, M. I. H. Linguagem e afasia: uma abordagem discursiva da Neurolinguística. Cadernos de Estudos Linguísticos, n. 42, pp. 99-129, jan-jun, 2002.

COUDRY, M. I. H.; FREIRE, F. M. P. O trabalho do cérebro e da linguagem: a vida em sala de aula. MEC: Cefiel/IEL/Unicamp, 2005.

COUDRY, M. I. H. Escrita: lugar de encontro entre afasia e infância. XVII Congreso Internacional Asociación De Lingüística Y Filología De América Latina (Alfal), João Pessoa, pp. 3490-3502, 2014. 
DE LEMOS, C. T. G. Interactional processes in the child's construction of language. In: W. Deustch (ed.). The Child Construction of Language. Cambridge: CUP, pp. 57-76, 1981.

DE LEMOS, C. T. G. Das vicissitudes da fala da criança e de sua investigação. Cadernos de Estudos Linguísticos. Campinas, n.42, pp. 41-69, 2002.

DE LEMOS, C. T. G. A criança e o linguista: modos de habitar a língua? Estudos linguísticos. São Paulo, 43 (2), pp. 954-964, maio-ago, 2014.

FOUCAULT, M. A ordem do discurso. São Paulo: Loyola, 2009 [1970].

FOUCAULT, M. O que é um autor? Ditos e Escritos: Estética - literatura e pintura, música e cinema (vol. III). Rio de Janeiro: Forense Universitária, pp. 264-298, 2001 [1969].

FRANCHI, C. Linguagem - atividade constitutiva. Almanaque 5, São Paulo: Brasiliense, pp. 9-27, 1977.

FRANCHI, C. Criatividade e gramática. Trabalhos de Linguística Aplicada, Campinas. v. 9, pp. 5-45, 1987.

JAKOBSON, R. A afasia como um problema linguístico. Novas Perspectivas Linguísticas. Petrópolis: Vozes, $3^{\text {a }}$ ed., pp. 43-54, 1973 [1955].

LIER-DE VITTO, M. F.; CARVALHO, G. M. de. O interacionismo: uma teorização sobre a aquisição da linguagem. In: FINGER, I.; QUADROS, R. M. de. (Orgs). Teorias de Aquisição da Linguagem, pp. 115-146, 2008.

LEITE,N.V.deA.Asletrasdatransmissão.2006.Disponível em $<$ http://www. fundamentalpsychopathology. org/anais2006/4.28.3.1.htm>. Acesso em: 04 abr. 2010.

MAINGUENEAU, D. Novas tendências em análise do discurso. Campinas: Pontes, 1989 [1987].

NASIO, J. -D. O que é um caso? In: NASIO, J. -D. (Org.) Os Grandes Casos de Psicose. Rio de Janeiro: Jorge Zahar, pp. 9-32, 2001.

ORLANDI, E. Apresentação. Cadernos de Estudos Linguísticos, n. 42, pp. 5-6, jan-jun, 2002.

PEROTTINO, S. Sob a condiçãto de não-falar de uma criança: a escrita de caso JM. Campinas, 2009. 210 f. Tese (Doutorado em Linguística) - Instituto de Estudos da Linguagem, Universidade de Campinas.

PEROTTINO, S. A escrita de caso na clínica de linguagem. Estudos linguísticos. São Paulo, São Paulo, 40 (2): pp. 581-594, maio-ago, 2011.

POSSENTI, S. O sujeito e a distância de si e do discurso. Os limites do discurso ensaios sobre discurso e sujeito. Curitiba: Criar Edições, pp. 123-135, 2002.

SAUSSURE, F. de. Curso de linguística geral. São Paulo: Cultrix, 2006 [1916].

SAUSSURE, F. de. Escritos de linguística geral. São Paulo: Cultrix, 2004 [2002]. 